\title{
Disproportionate elevation of immunoreactive proinsulin in Type 2 (non-insulin-dependent) diabetes mellitus and in experimental insulin resistance
}

\author{
W.K. Ward ${ }^{1,2}$, E.C. LaCava ${ }^{1,2}$, T.L.Paquette ${ }^{1}$, J.C. Beard ${ }^{1,2}$, B.J. Wallum ${ }^{1,2}$ and D. Porte, Jr., ${ }^{1,2}$ \\ ${ }^{1}$ Division of Metabolism, Endocrinology and Nutrition, Department of Medicine, University of Washington and the \\ ${ }^{2}$ Veterans Administration Medical Center, Seattle, Washington, USA
}

\begin{abstract}
Summary. In this study, we found that the ratio of proinsulin to total immunoreactive insulin was much higher in 22 patients with Type 2 (non-insulin-dependent) diabetes mellitus than in 28 non-diabetic control subjects of similar age and adiposity ( $32 \pm 3$ vs $15 \pm 1 \%, p<0.001)$. In addition, the arginine-induced acute proinsulin response to total immunoreactive insulin response ratio was greater in diabetic patients $(n=10)$ than in control subjects $(n=9)(8 \pm 2$ vs $2 \pm 0.5 \%$, $p=0.009$ ), suggesting that increased islet secretion per se accounted for the increased ratio of proinsulin to immunoreactive insulin. One explanation for these findings is that increased demand for insulin in the presence of islet dysfunction leads to a greater proportion of proinsulin secreted from the $\mathrm{B}$ cell. We tested this hypothesis by comparing proinsulin secretion before and during dexamethasone-induced insulin resistance in diabetic patients and control subjects. Dexamethasone treatment $(6 \mathrm{mg} /$ day for 3 days $)$ raised the proinsulin to immunoreactive insulin ratio in control subjects from $13 \pm 2$ to $21 \pm 2 \%(p<0.0001)$ and in diabetic patients
\end{abstract}

from $29 \pm 5$ to $52 \pm 7 \%(p<0.001)$. Dexamethasone also raised the ratio of the acute proinsulin response to the acute immunoreactive insulin response in control subjects from $2 \pm 0.5$ to $5 \pm 2 \%(p=0.01)$ and in diabetic patients from $8 \pm 2$ to $14 \pm 4 \%(p=\mathrm{NS})$, suggesting that the dexamethasone-induced increment in the basal ratio of proinsulin to immunoreactive insulin was also due to increased secretion. We conclude that: (1) The basal proinsulin to immunoreactive insulin ratio is increased in obese Type 2 diabetic patients. (2) An increase in tissue demand for insulin leads to a rise in the proinsulin to immunoreactive insulin ratio, which is exaggerated in Type 2 diabetic patients. (3) The increased proinsulin to immunoreactive insulin ratio in these diabetic patients in the basal state and in diabetic patients and control subjects during experimental insulin resistance is probably due to increased B-cell secretion of proinsulin.

Key words: Type 2 (non-insulin-dependent) diabetes, proinsulin, insulin resistance, dexamethasone, arginine.
Duckworth et al. reported in 1972 that, after an oral glucose challenge, obese Type 2 diabetic patients exhibited a larger rise in the proinsulin to total insulin ratio than nondiabetic control subjects [1]. Later, both Gordon et al. [2] and Mako et al. [3] observed that the basal ratio of proinsulin to total insulin was also elevated in many Type 2 diabetic patients. A plausible explanation for these findings is that a great demand for insulin secretion, when accompanied by B-cell secretory dysfunction, leads to hypersecretion of proinsulin [1-3]. A mechanism by which proinsulin hypersecretion could occur is through the depletion of mature insulin-rich granules leading to hypersecretion of newly synthesized proinsulin-rich granules.

In the present study, we tested the hypothesis that an increase in insulin demand would lead to a greater rise of proinsulin in Type 2 diabetic patients than in non-diabetic subjects. To increase demand for insulin, we have given a three-day course of dexamethasone, which is known to create tissue resistance to insulin [4, 5]. To assess whether proinsulin rises disproportionate- ly in Type 2 diabetes, we report ratios of proinsulin to total insulin before and during dexamethasone in diabetic patients and normal subjects. Further, since measurement of basal proinsulin does not allow assessment of the contributions of secretion and clearance to proinsulin values, we also measured the proinsulin and total insulin secretory responses to arginine in both groups before and during dexamethasone.

\section{Subjects and methods}

\section{Subjects}

Basal studies were performed in 22 patients with Type 2 diabetes and in 28 nondiabetic subjects. No patient was taking a pharmacologic agent for treatment of diabetes and no patient was on a weight-reduction diet at the time of this study. Six of the patients had previously been treated with sulfonylureas, but no patient had received these drugs within 30 days of the present study. Diabetes was diagnosed in each patient at least one year prior to this study according to criteria of the National Diabetes Data Group [6]. Ten of the diabetic patients, two of whom had been previously treated with sul- 
Table 1. A comparison of male/female ratio (M/F), age, height, body mass index $\left(\mathrm{kg} / \mathrm{m}^{2}, \mathrm{BMI}\right)$, and fasting plasma glucose (FPG) in Type 2 (non-insulin-dependent) diabetic patients and non-diabetic control subjects (Dexamethasone $=$ Dex)

\begin{tabular}{|c|c|c|c|c|c|c|}
\hline & $n$ & $\mathrm{M} / \mathrm{F}$ & $\begin{array}{l}\text { Age } \\
\text { (years) }\end{array}$ & $\begin{array}{l}\text { Height } \\
\text { (cm) }\end{array}$ & $\begin{array}{l}\text { BMI } \\
\left(\mathrm{kg} / \mathrm{m}^{2}\right)\end{array}$ & $\begin{array}{l}\text { FPG } \\
(\mathrm{mmol} / \mathrm{l})\end{array}$ \\
\hline \multicolumn{7}{|c|}{ Diabetic patients } \\
\hline All subjects & 22 & $21 / 1$ & $58 \pm 2$ & $173 \pm 2$ & $28.5 \pm 0.73$ & $11.8 \pm 0.84$ \\
\hline $\begin{array}{l}\text { Dex study } \\
\text { subset }\end{array}$ & 10 & $9 / 1$ & $62 \pm 2$ & $170 \pm 3$ & $29.5 \pm 1.1$ & $9.8 \pm 1.1$ \\
\hline \multicolumn{7}{|l|}{ Control subjects } \\
\hline All subjects & 28 & $23 / 5$ & $52 \pm 4$ & $172 \pm 2$ & $26.6 \pm 0.84$ & $5.3 \pm 0.11$ \\
\hline $\begin{array}{l}\text { Dex study } \\
\text { subset }\end{array}$ & 9 & $7 / 2$ & $60 \pm 2$ & $168 \pm 3$ & $28.4 \pm 1.4$ & $5.8 \pm 0.11$ \\
\hline
\end{tabular}

fonylureas, and nine of the nondiabetic control subjects participated in the dexamethasone study. A comparison of age, height, body mass index, and fasting plasma glucose in all the subjects and in those who underwent the dexamethasone study is shown in Table 1. Most of the diabetic patients and control subjects were obese. None of the control subjects had a personal or family history of diabetes in siblings or parents. Prior approval for all studies was given by the University of Washington Human Subjects Review Committee, and each subject gave written informed consent before participation.

\section{Dexamethasone study}

The dexamethasone study was performed while subjects were inpatients at the University of Washington Clinical Research Center. Baseline samples were taken and arginine stimulation tests performed before, and $72 \mathrm{~h}$ after, beginning oral dexamethasone. Each of these studies was initiated at 07.00 to 09.00 hours after a 12 -h fast. In the predexamethasone study, a 16- to 18-gauge teflon catheter was inserted into a wrist vein for purposes of blood withdrawal. The hand and wrist were enclosed in a warming box which was thermostatically maintained at $60^{\circ} \mathrm{C}$ in order to arterialise the blood. A similar catheter was inserted into a forearm or antecubital vein of the contralateral arm and used for infusion of compounds.

In order to avoid marked dexamethasone-induced hyperglycaemia during hormone measurements, five of the more hyperglycaemic diabetic patients received a 60 - to 120 -min infusion of purified pork regular insulin (Velosulin, Nordisk, Copenhagen, Denmark) at a rate of $2 \mu \mathrm{U} \cdot \mathrm{kg}^{-1} \cdot \mathrm{min}^{-1}$, followed by a $120 \mathrm{~min}$ insulin washout period immediately prior to blood sampling studies. The same insulin infusion was given in the absence and presence of dexamethasone administration. We have previously shown that a prior insulin infusion, when followed by such a washout period, does not by itself alter the insulin response to arginine in diabetic patients [7].

Thirty minutes after catheter insertion, or $120 \mathrm{~min}$ after termination of the insulin infusion, two baseline samples were obtained 5 min apart for measurement of glucose, insulin, and proinsulin. A $5 \mathrm{~g}$ bolus of arginine $\mathrm{HCl}$ was then delivered intravenously over $30 \mathrm{~s}$. Blood samples for measurement of insulin and proinsulin were obtained 2, 3, 4, 5, 7, and 10 min after the arginine bolus. Blood samples, which were drawn into tubes containing EDTA, were placed on ice then centrifuged at $4^{\circ} \mathrm{C}$, and the plasma was stored at $-20^{\circ} \mathrm{C}$ until assay at a later date.

Insulin secretory responses to nonglucose stimuli such as arginine are affected by circulating glucose level [8]. Thus, acute insulin and proinsulin responses to arginine were measured in control subjects at a glucose level which was at least as high as that in the diabetic patients. To do so, after the first arginine bolus and blood sampling period, an infusion of $10 \%$ dextrose (with $10 \mathrm{meq} \mathrm{KCl} / \mathrm{l}$ ) was given to control subjects in order to raise the glucose level to approximately $17 \mathrm{mmol} / 1$ and maintain it at that level. Forty minutes after beginning this hyperglycaemic clamp, a second arginine $\mathrm{HCl}$ bolus was delivered and samples were obtained as above.
After this first insulin secretion study, $3 \mathrm{mg}$ of dexamethasone were given twice daily by mouth for 3 days. On the morning of the second day after beginning dexamethasone, an islet secretion study identical to the first was repeated.

\section{Biochemical measurements}

Plasma glucose was measured by the glucose oxidase method (Autoanalyzer, Beckman Instruments, Brea, Calif, USA). Total plasma insulin was measured by a modification of the double antibody method of Morgan and Lazarow [9]. Proinsulin was measured as previously described [10]. Briefly, in this assay, immunoactive proinsulin is first separated from plasma by use of an excess of anti-human-C-peptide antiserum. An immunoprecipitate is then formed by using a precipitating antiserum and polyethylene glycol, after which immunoreactive proinsulin is dissociated from the precipitate by incubation in warm $\mathrm{HCl}, \mathrm{pH} 2.0$. The resulting mixture is assayed for insulin immunoreactivity by a double antibody tracer competition method involving incubation for 4 days with a high-affinity antiinsulin antiserum. Human proinsulin of recombinant DNA origin is used as standards (courtesy of Dr. Bruce Frank, Lilly Laboratories, Indianapolis, Ind, USA). The detection limit for immunoreactive proinsulin (two standard deviations from 0-dose binding) is $3 \mathrm{pmol} / 1$.

\section{Calculations}

In our standard assay for immunoreactive insulin (IRI), proinsulin reacts $100 \%$ as well as insulin on a molar basis [10]. In contrast, insulin reacts very weakly in the proinsulin assay (approximately $1 \%$; the exact crossreactivity is determined separately in each assay) [10]. Thus to determine true insulin (I) and true proinsulin (PI), simultaneous equations are solved which subtract the contribution of proinsulin from total IRI and the contribution of insulin from immunoreactive proinsulin in each plasma sample [9]. The designations "insulin (I)" and "proinsulin (PI)", i. e. not preceded by "immunoreactive", refer to these corrected values. The designations "immunoreactive insulin (IRI)" or "immunoreactive proinsulin (IRPI)" refer to total, uncorrected values.

The acute total immunoreactive insulin response to arginine (AIRIR) was determined as the area above baseline under the total IRI curve from $0-10 \mathrm{~min}$ after the arginine bolus. Similarly, acute insulin responses (AIR) and acute proinsulin responses (APIR) to arginine were measured as $0-10 \mathrm{~min}$ areas under respective curves. For the control subjects, the percentages of AIRIR due to the APIR were not significantly different at the lower and upper glucose levels, therefore the mean percentage at the two glucose levels was used to compare APIR/AIRIR before dexamethasone to the ratio during dexametheasone. All the hormone values are expressed in pmol/1 for ease of comparison (for insulin, $1 \mu \mathrm{U} / \mathrm{ml}=6.67 \mathrm{pmol} / 1$ ).

\section{Statistical analysis}

Student's paired or unpaired t-tests were used to compare differences. A level of 0.05 was taken as establishing significance. Results are expressed as mean \pm SEM.

\section{Results}

Basal PI was markedly greater in Type 2 diabetic patients than in nondiabetic control subjects $(30 \pm 4$ vs $11 \pm 7 \mathrm{pmol} / 1, p<0.001)$. In contrast, basal insulin in diabetic patients was slightly, but not significantly, lower than in control subjects $(61 \pm 6$ vs $71 \pm 6 \mathrm{pmol} / \mathrm{l})$. The PI/IRI ratio was also greater in the diabetic patients than in control subjects $(32 \pm 3$ vs $15 \pm 1 \%, p<$ 0.001, Fig. 1). 
Table 2. A comparison of plasma glucose (PG), proinsulin (PI), insulin (I), PI as a percentage of total immunoreactive insulin (PI/IRI), the acute PI response to arginine (APIR), the acute I response to arginine (AIR), and the APIR as a percentage of the total IRI response to arginine (APIR/AIRIR) in non-diabetic control subjects and Type 2 (non-insulin-dependent) diabetic patients both before and during dexamethasone (Dex) treatment

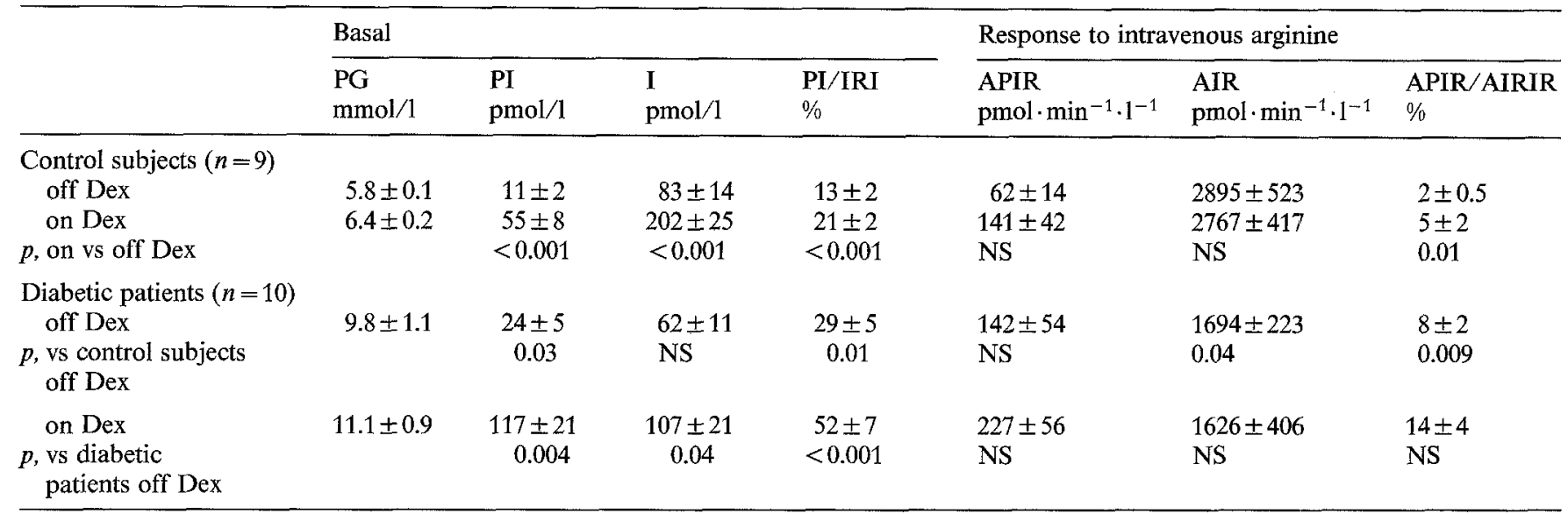

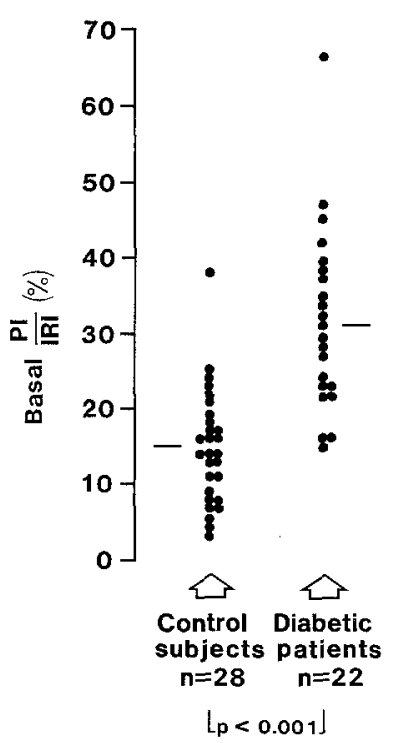

Fig. 1. A comparison of basal ratios of proinsulin (PI) to total immunoreactive insulin (IRI) in control subjects and Type 2 (non-insulin-dependent) diabetic patients

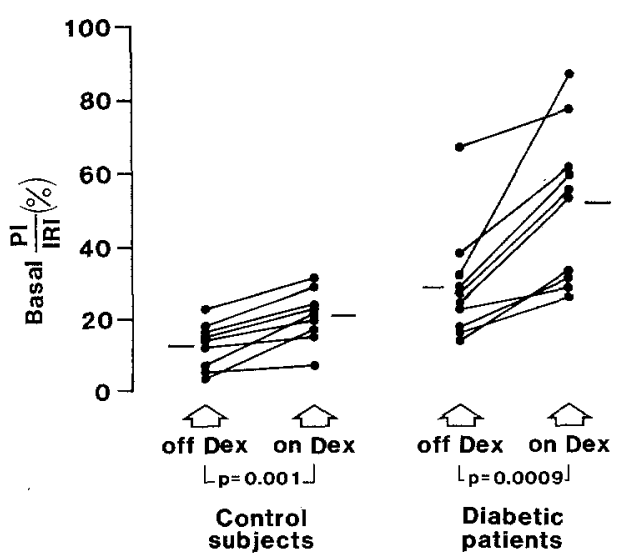

Fig. 2. A comparison of basal ratios of proinsulin (PI) to total immunoreactive insulin (IRI) off and on dexamethasone (Dex) in 9 control subjects and 10 Type 2 (non-insulin-dependent) diabetic patients

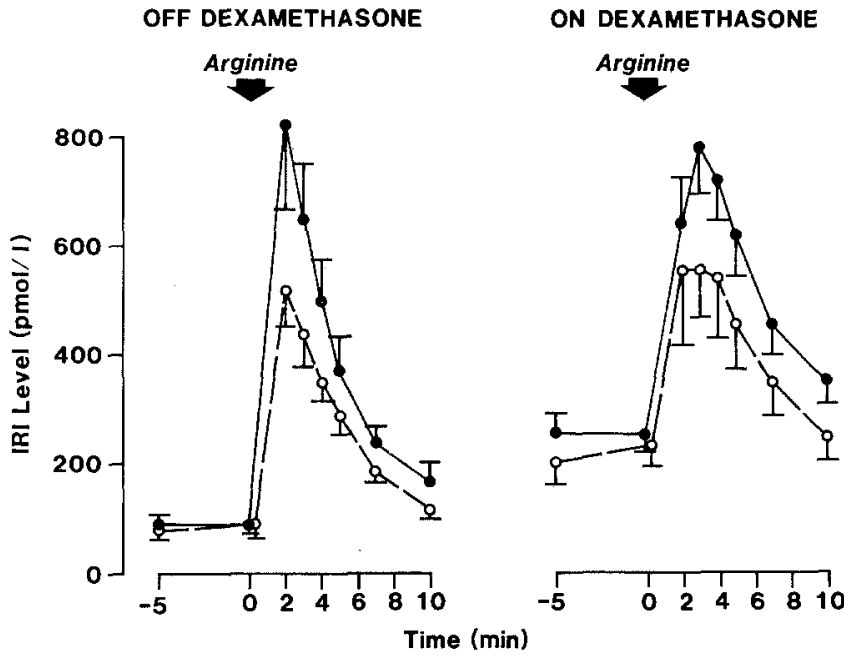

Fig. 3. A comparison of total immunoreactive insulin levels (IRI) before and after a $5 \mathrm{~g}$ bolus of intravenous arginine off and on dexamethasone in control subjects and Type 2 (non-insulin-dependent) diabetic patients. Control subjects, $n=9 ; 0$ -..$--O$ Diabetic patients, $n=10$ mean \pm SEM

Mean basal hormone values before and during dexamethasone treatment are shown in Table 2. In control subjects and diabetic patients, dexamethasone treatment led to significant rises in PI, I, and PI/IRI ratios. After dexamethasone, PI accounted for $52 \%$ of total IRI in diabetic patients. In addition, the dexamethasone-induced rise in the percentage of IRI accounted for by PI (PI/IRI) was greater in the diabetic patients than in control subjects $(23 \pm 5$ vs $8 \pm 2 \%$, $p=0.02$ ). Individual values for PI/IRI off and on dexamethasone are depicted in Figure 2.

Mean hormone responses to arginine are also shown in Table 2 and Figures 3 and 4. There was a tendency for the predexamethasone APIR to be higher in diabetic patients than in control subjects $(142 \pm 54$ vs $62 \pm 14 \mathrm{pmol} \cdot \min \cdot 1^{-1}$ ), but this difference was not significant. However, the predexamethasone APIR/AI- 


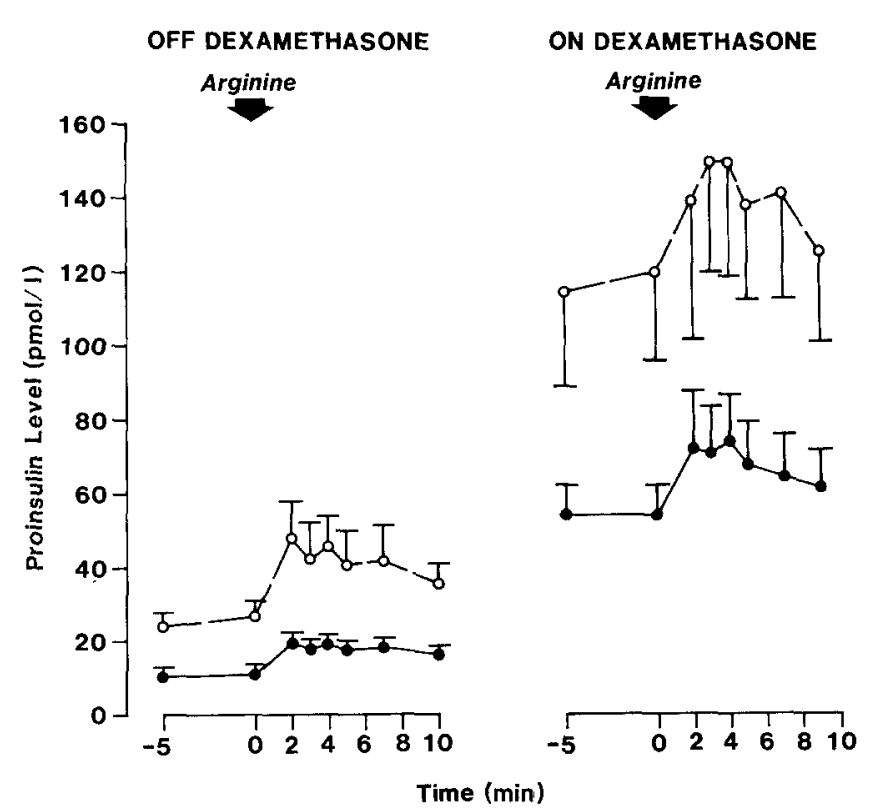

Fig.4. A comparison of proinsulin levels (corrected for insulin crossreactivity, see text) before and after a 5 - $\mathrm{g}$ bolus of intravenous arginine off and on dexamethasone in control subjects and Type 2 (non-insulin-dependent) diabetic patients. Note larger proinsulin response to arginine while on dexamethasone, which is exaggerated in the diabetic patients. $\longrightarrow$ Control subjects, $n=9 ; 0-$. Diabetic patients, $n=10$ mean \pm SEM

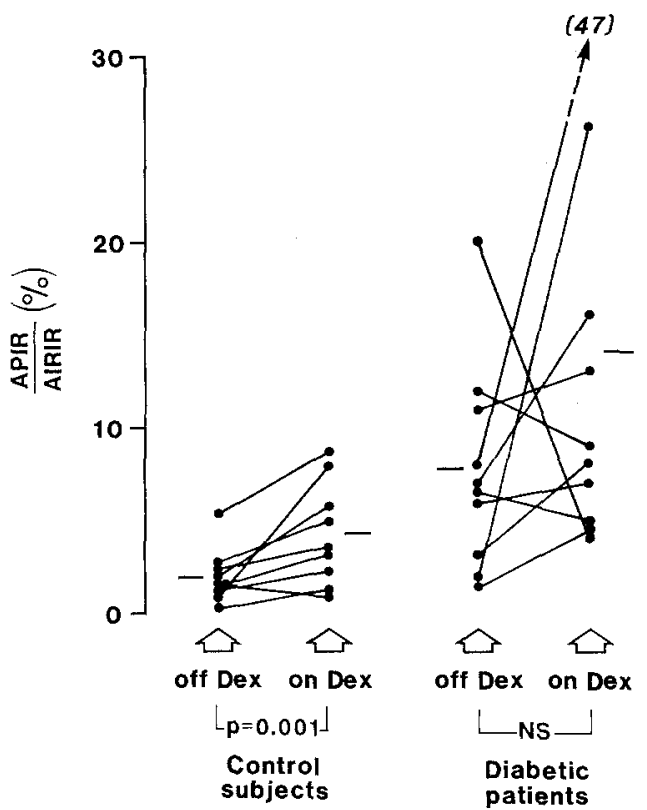

Fig.5. A comparison of ratios of the arginine-induced acute proinsulin response (APIR) to acute total immunoreactive insulin response (AIRIR) off and on dexamethasone (Dex) in 9 control subjects and 10 Type 2 (non-insulin-dependent) diabetic patients

RIR ratio was significantly greater in diabetic patients than in control subjects ( $8 \pm 2$ vs $2 \pm 0.5 \%, p=0.009$ ). In addition, there were nonsignificant trends for dexamethasone to increase the APIR in both groups. Dexamethasone induced a significant rise in the percentage of the total IRI response accounted for by a PI response in control subjects (APIR/AIRIR, from $2 \pm$
0.5 to $5 \pm 2 \%$ ). In diabetic patients, dexamethasone also induced a rise in APIR/AIRIR (from $8 \pm 2$ to $14 \pm$ $4 \%$ ), but this difference was not significant. Individual APIR/AIRIR values on and off dexamethasone are shown for both groups in Figure 5.

Control subjects also underwent arginine stimulation after clamping glucose at $16.8 \pm 0.73$ before dexamethasone and $16.7 \pm 0.56 \mathrm{mmol} / 1$ during dexamethasone. Although absolute PI and I levels were, of course, higher at these hyperglycaemic levels, the prestimulus PI/IRI and post-challenge APIR/AIRIR ratios at hyperglycaemic levels were not significantly different from ratios obtained in the same control subjects at euglycaemia. The PI/IRI ratio obtained at hyperglycaemia was $8 \pm 0.6$ before dexamethasone and $10 \pm 2 \%$ after dexamethasone. The AIR/AIRIR was $1.8 \pm 0.6$ before dexamethasone and $4.1 \pm 1 \%$ after dexamethasone.

\section{Discussion}

Mature secretory granules in the islet B cell are thought to contain a small, fixed amount of proinsulin which has not been cleaved to insulin and C-peptide. Thus, in general, as the B cell increases or decreases its secretion of insulin, it might be expected to also increase or decrease secretion of proinsulin in a proportionate fashion. However, Type 2 patients in this study were found to have an elevated basal PI/IRI ratio which was twice that of control subjects ( 32 vs $15 \%$ ). This agrees with the previous finding of Mako et al. who found that Type 2 diabetic patients with plasma glucose levels greater than $9.5 \mathrm{mmol} / 1$ tended to have a PI/IRI ratio of greater than $25 \%$ [3]. In addition, Duckworth et al. reported that oral glucose induced a greater rise in proinsulin-like material in obese Type 2 diabetic patients than in nondiabetic control subjects [1]. The hypothesis given for such increases in percentage of proinsulin has been that increased demand for insulin in patients with islet dysfunction leads to secretion of immature, proinsulin-rich granules [1-3].

In a study of nondiabetic subjects, Kitabchi et al. observed that hydrocortisone therapy led to a substantial increase in the proinsulin response to oral glucose [11]. Our study confirms this finding in normal subjects and also examines the effect of corticosteroids on proinsulin secretion in Type 2 diabetic patients. Notably, diabetic patients, as compared to nondiabetic control subjects exhibited a significantly larger rise in the ratio of proinsulin to total insulin during dexamethasone treatment. Thus, it appears that an increased demand for insulin over a period of several days leads to a modest rise in the circulating ratio of PI/IRI in subjects with normal islet function, but that in individuals whose capacity to store insulin is limited [7], this rise is even larger. In an animal study, Pierlussi et al. [12] also showed a disproportionate elevation in proinsulin levels during insulin resistance. They dem- 
onstrated a mean rise in PI/IRI ratio from $29 \%$ to $49 \%$ after one day of growth hormone treatment in dogs. Although effects of growth hormone on proinsulin or insulin clearance were not ruled out in this study, their results, like ours, suggest that tissue resistance to insulin leads to an increase in the percentage of proinsulin secreted.

The ratio of circulating PI/IRI is controlled by four factors, i. e. the rates of secretion and clearance of both proinsulin and insulin. To better assess the cause of the elevated PI/IRI ratio in Type 2 diabetic patients, using a measure little affected by variations in clearance, we also measured the acute secretory response of proinsulin and insulin to intravenous arginine in both groups. The ratio of APIR to the total IRI response was significantly greater in diabetic patients $(8 \%)$ than in control subjects $(2 \%)$. This difference demonstrates increased secretion of proinsulin in Type 2 diabetic patients as compared to control subjects and suggests that the patients' elevated PI/IRI ratio is due to hypersecretion of proinsulin. In addition, the ratio of the APIR to the total IRI response increased both in control subjects (significantly) and in diabetic patients (nonsignificantly) during dexamethasone, as compared to before dexamethasone. These findings support the idea that the dexamethasone-induced rise in basal PI/IRI was due to increased islet secretion of proinsulin. However, since clearance was not measured directly, reduced clearance may also have contributed to the elevated IRP/IRI ratios seen in diabetic patients and seen in both groups after dexamethasone. Of note is that the short period of hyperglycaemia created in this study by a 40 -min hyperglycaemic clamp in control subjects did not increase the ratio of APIR to the total IRI response. It thus appears that in nondiabetic control subjects, either longer periods of increased demand are needed to create the rise in APIR or that hyperglycaemia is not the specific signal which causes disproportionate secretion of proinsulin during dexamethasone treatment.

The elevation in PI/IRI ratio in Type 2 diabetic patients and its exaggeration by corticosteroid treatment suggest the possibility that a disproportionate increase in proinsulin secretion during increased demand may be useful as an indication of early B-cell dysfunction. It would certainly be helpful to have a better and more sensitive means of detecting individuals prone to B-cell decompensation than is presently available. Indeed, it has been suggested that an increased PI/IRI ratio might predict which patients with incipient Type 1 (insulin-dependent) diabetes may soon require insulin [13], although the data is far from conclusive. One possibility which we are currently testing is that euglycaemic patients who are highly predisposed to Type 2 diabetes, like those with overt Type 2 diabetes, will have a disproportionate increase in proinsulin secretion in response to dexamethasone.

In summary, Type 2 diabetic patients demonstrated higher basal proinsulin to IRI ratios than control subjects and higher arginine-induced proinsulin response to total IRI response ratios. In addition, oral dexamethasone induced a rise in PI/IRI which was modest in control subjects and marked in diabetic patients. We conclude that: (1) increased tissue demand for insulin leads to a rise in PI/IRI ratio, which is exaggerated in the presence of islet B-cell dysfunction; and (2) the increased PI/IRI ratio in Type 2 diabetic patients in the basal state and in diabetic patients and control subjects during experimental insulin resistance is probably due to increased B-cell secretion of proinsulin.

Acknowledgements. We thank L Parry, D Balderama, and D Sawin for preparation of the manuscript, L Guthrie for editorial assistance, and $\mathbf{L}$ Merkeley and $J$ Wade for expert technical assistance. This work was supported by NIH Grants AM-12829, AM-17047, RR-37 and the Medical Research Service of the Veterans Administration.

\section{References}

1. Duckworth WC, Kitabchi AE, Heinemann M (1972) Direct measurement of plasma proinsulin in normal and diabetic subjects. Am J Med 53: 418-427

2. Gordon P, Hendricks CM, Roth J (1974) Circulating proinsulinlike component in man: increased proportion in hypoinsulinemic states. Diabetologia 10: 469-474

3. Mako ME, Starr JI, Rubenstein AH (1977) Circulating proinsulin in patients with maturity-onset diabetes. Am J Med 63: 865-869

4. Yasuda K, Hines E, Kitabchi AE (1982) Hypercortisolism and insulin resistance: comparatiave effects of prednisone, hypdrocortisone and dexamethasone on insulin binding of human erythrocytes. J Clin Metab 55: 910-915

5. Lenzen S, Bailey CJ (1984) Thyroid hormones, gonadal and adrenocortical steroids and the function of the islets of Langerhans. Endocr Rev 5: 411-434

6. National Diabetes Data Group (1979) Classification and diagnosis of diabetes mellitus and other categories of glucose intolerance. Diabetes 28: 1039-1057

7. Ward WK, Bolgiano DC, McKnight B, Halter JB, Porte D Jr (1984) Diminished B-cell secretory capacity in patients with noninsulin dependent diabetes mellitus. J Clin Invest 74: 1318-1328

8. Halter JB, Graf RJ, Porte D Jr (1979) Potentiation of insulin secretory responses by plasma glucose levels in man: evidence that hyperglycemia compensates for impaired glucose potentiation. J Clin Endocrinol Metab 48: 946-954

9. Morgan CR, Lazarow A (1963) Immunoassay of insulin: two-antibody system. Diabetes 12: 115-126

10. Ward WK, Paquette TL, Frank BH, Porte D Jr (1986) A sensitive radioimmunoassay for human proinsulin, with sequential use of anti-C-peptide and anti-insulin antisera. Clin Chem 32: 728-733

11. Kitabchi AE, Jones GM, Duckworth WC (1973) Effect of hydrocortisone and corticotropin on glucose-induced insulin and proinsulin secretion in man. J Clin Endocrinol Metab 37: 79-84

12. Pierlussi J, Campbell J (1981) Growth hormone and metasomatrophic diabetes: effects on insulin and proinsulin of serum and pancreas in dogs. Diabetologia 21: $558-562$

13. Ludvigsson J, Heding L (1982) Abnormal proinsulin/C-peptide ratio in juvenile diabetes. Acta Diabetol Lat 19:351-358

Received: 10 March 1987

and in revised form: 24 July 1987

Dr. Ward

Portland Diabetes Center

2232 N.W. Pettygrove Ave.

Portland, OR 97210

USA 